http://artnodes.uoc.edu

\title{
La cognición expresiva como experiencia de relación del arte y la ciencia en la educación preuniversitaria
}

\author{
Martin Caeiro Rodríguez \\ Antonia María Muñiz de la Arena \\ UNIR-Universidad Internacional de La Rioja
}

Fecha de presentación: octubre de 2018

Fecha de aceptación: mayo de 2019

Fecha de publicación: julio de 2019

\section{Cita recomendada}

Caeiro Rodríguez, Martin; Muñiz de la Arena, María Antonia. 2019. «La cognición expresiva como experiencia de relación del arte y la ciencia en la educación preuniversitaria». Artnodes. N. ${ }^{0}$ 24: 142-154. UOC [Fecha de consulta: dd/mm/aa]. http://dx.doi.org/10.7238/a.v0i24.3259

\section{(c)} SOMIERIGHISRESERVED
Los textos publicados en esta revista están sujetos -si no se indica lo contrario- a una licencia de Reconocimiento 4.0 Internacional de CreativeCommons. La licencia completa se puede consultar en https://creativecommons.org/licenses/by/4.0/deed.es_ES.

\section{Resumen}

La epistemología visual estudia aquellas imágenes que son vehículo de conocimiento tanto en el arte como en la ciencia. No obstante, también hay un pensamiento y conocimiento plástico, que se significa a través de objetos diversos, y que podemos disfrutar y experimentar en exposiciones y museos de ciencia o de arte y que se practica en contextos tanto científicos como artísticos. Nuestro recorrido por la cognición expresiva (visual y plástica) identifica, desde una metodología descriptiva y comprensiva, las posibilidades que rigen en este modo de conocer y pensar a través de imágenes y objetos, en los cuales se produce la «episteme» o lo que Jean Piaget identificó como «representación cognoscitiva», y que podemos encontrar tanto en el arte como en la ciencia. Del análisis de imágenes y objetos se deduce que existen prácticas y proyectos cuyas acciones articulan cognición y expresión, conectando la comprensión científica y las prácticas inherentes a los procesos de creación artística. A partir de la revisión teórica y visual, se significa la oportunidad de introducir en el contexto educativo 


\title{
artnodes
}

http://artnodes.uoc.edu

La cognición expresiva como experiencia de relación del arte...

preuniversitario espacios de aprendizaje que sean al mismo tiempo cognitivos y expresivos. Estas acciones educativas permitirán a los discentes adquirir de forma progresiva consciencia de que la creación de imágenes o de objetos, desde un proceso de cognición expresiva, puede llevar a una mejor comprensión de fenómenos tan complejos como la relatividad, una neurona o el ADN, o de conceptos tan abstractos como la dimensión del tiempo.

\section{Palabras clave}

ilustración y cognición, representación cognoscitiva, arte y ciencia, epistemología visual, plástica y educación

\section{Expressive cognition as a relationship experience of art and science in pre-university education}

\begin{abstract}
Visual epistemology studies images that are vehicles of knowledge in both art and science. However, there is also plastic thought and knowledge that is meant through diverse objects which we can enjoy and experience in science and art exhibitions and museums that is carried out in both scientific and artistic contexts. From a comprehensive descriptive methodology, our journey through expressive (visual and plastic) cognition identifies the possibilities that govern this way of knowing and thinking through images and objects in which the "episteme" is produced or what Jean Piaget identified as "cognitive representation", and that we can find in both art and science. Based on the analysis of images and objects, we can deduce that there are practices and projects whose actions articulate cognition and expression, connecting scientific understanding and practices inherent to the processes of artistic creation. Based on theoretical and visual revision, it means the opportunity to introduce learning spaces that are both cognitive and expressive at the same time in the pre-university educational context. These educational actions will allow learners to progressively become aware that creating images and objects from an expressive cognition process can lead to a better understanding of phenomena as complex as relativity, neurons and DNA as well as abstract concepts such as the dimension of time.
\end{abstract}

\section{Keywords}

illustration and cognition, cognitive representation, art and science, visual epistemology, plastic and education

\section{Introducción: lo alfabético y numérico junto a lo plástico y visual}

Las ilustraciones están presentes en diversos contextos del arte y de la ciencia en forma de esquemas, dibujos, grabados, pinturas, fotografías... y han acompañado históricamente a textos científicos representando en un lenguaje visual experimentos y descubrimientos diversos. Cuando hablamos de ilustración científica nos referimos a un tipo de registro muy detallado, realizado con el propósito de reafirmar visualmente ideas, fenómenos o teorías fruto de investigaciones llevadas a cabo en disciplinas como: la astronomía, la arqueología, la medicina, la botánica, la zoología, la neurología, etcétera. Este tipo de ilustraciones tienen la función de representar y expresar una información concreta y objetiva (Daston y Galison 1992). En el contexto artístico, la ilustración aparece como un género propio y una profesión que permite comprender visualmente conceptos tan abstractos como la locura 0 el acoso, dar forma y significado visual a épocas y sociedades y, por supuesto, la encontramos en uno de los espacios que más se ha enriquecido en los últimos años: Ios álbumes ilustrados. En este sentido, no debemos confundir la epistemología visual ni el pensamiento visual, ni mucho menos la cognición expresiva, con el denominado visual thinking, cuyo propósito principal es comunicar ideas y pensar conceptos visualmente y no tanto generar conocimiento 0 dar a conocer fenómenos. Además, las imágenes 


\section{artnodes}

http://artnodes.uoc.edu

La cognición expresiva como experiencia de relación del arte...

epistemológicas suelen generase desde la práctica experta del ilustrador, fotógrafo, realizador, dibujante... y articulan un pensamiento perceptual (Arnheim 1971; Berger 2013), que explora y comprende por medio de la acción y la manipulación plástica antes que ser la consecuencia de un pensamiento de entretenimiento o condicionado al proceso comunicativo (espectador, mensaje, emisor). Por cognición expresiva también nos referimos a objetos que incorporan un valor epistémico en su configuración, construidos por procesos y técnicas plásticas comunes al arte y a la ciencia con el propósito de manipularlos y observarlos en tres o cuatro dimensiones, es decir, pensarlos objetual, sensitiva y multisensorialmente.

Tampoco nos referiremos con cognición expresiva al discurso filosófico, ideológico o estético de las artes en relación con sus productos (Althusser 1966; Brea et al. 2005) 0 a la idea de estar frente a un conocimiento objetivo artístico definido desde la «Epistemología del Arte» (Sánchez et al. 2013). Nos interesa significar aquí lo que ocurre en el proceso de creación en sí y lo que su práctica aportará a la «mentalidad» del niño al realizar estas imágenes y objetos, a los procesos de plasticidad y visualidad que configuran la «episteme» y no tanto al plano del discurso. Jean Piaget denominó «representación cognoscitiva» (Piaget 1973) a la capacidad que sucede y complementa las operaciones sensorio-motoras, a la adquisición del pensamiento simbólico, en la que el niño adquiere el pensamiento conceptual 0 «inteligencia representativa», donde traduce a esquemas conceptuales, verbales o intelectuales esquemas sensibles u operacionales. En nuestro enfoque, consideramos la imagen y el objeto como dispositivos que desencadenan procesos de visualidad y plasticidad al mismo tiempo que aprendemos, y que articulan en su configuración, ya desde las operaciones sensorio-motoras, un saber que no es sólo conceptual, sino también corpóreo y sensitivo, y donde los conocimientos adquiridos formal, espacial y temporalmente condicionan e influyen en el propio acto o modo de pensar.

La cognición expresiva, como veremos, se manifiesta como una actividad que enlaza representación y pensamiento desde lo procesual, sin poder separar la primera operación de la segunda en el relato que presenta (Baigri 1996). Esto adquiere especial relevancia si nos situamos en el contexto educativo y formativo de los discentes y en sus primeras etapas de desarrollo (véase Piaget 1977; Luquet 1926; Lowenfeld y Lambert 1972; Vigotsky 2014). No obstante, esta doble función de conocer y expresar que adquieren las imágenes y objetos ha quedado relegada en la actualidad al contexto universitario y para titulaciones artísticas, disciplinas o carreras científicas que requieran cierto dominio de la expresión gráfica y del dibujo, como son Bellas Artes, Artes Plásticas y Visuales, Zoología, Botánica, Mineralogía, Arqueología o Topología y carece de espacio específico en el contexto preuniversitario. Cuando se trabaja la ilustración en Educación Primaria o Secundaria, suele considerarse un medio útil para expresar relatos, poner imágenes a textos y a narrativas orales, lo cual, siendo necesario, resulta insuficiente en el contexto de la sociedad del cono- cimiento. Y en relación con lo escultórico, poco podemos hacer si el maestro utiliza la hora semanal de «plástica» para hacer un portafotos de barro 0 un collar con macarrones, confundiendo las artes con la producción de abalorios (Acaso 2009), o sitúa de forma generalizada las artes en el contexto del ocio y del entretenimiento mediático.

En este contexto, el objetivo general de este trabajo es establecer el marco de la cognición expresiva visual y plástica, y poner en valor lo que aportaría al desarrollo cognitivo y expresivo de los niños con su práctica temprana. Para ello, investigamos sobre la función epistémica que adquieren la ilustración y lo escultórico, tanto en el contexto de la ciencia como en el contexto del arte, con ejemplos artísticos y científicos; profundizamos en la representación visual y plástica del tiempo, la codificación icónica y abstracta de fenómenos complejos; e identificamos recursos gráficos y plásticos ideados por artistas y científicos para materializar sus descubrimientos como complemento al lenguaje verbal y alfabético. Finalmente, consideraremos si es deseable y necesario el diseño de proyectos que integren ciencia y arte que articulen las posibilidades y necesidades de ambos contextos desde un enfoque cognitivo y expresivo común.

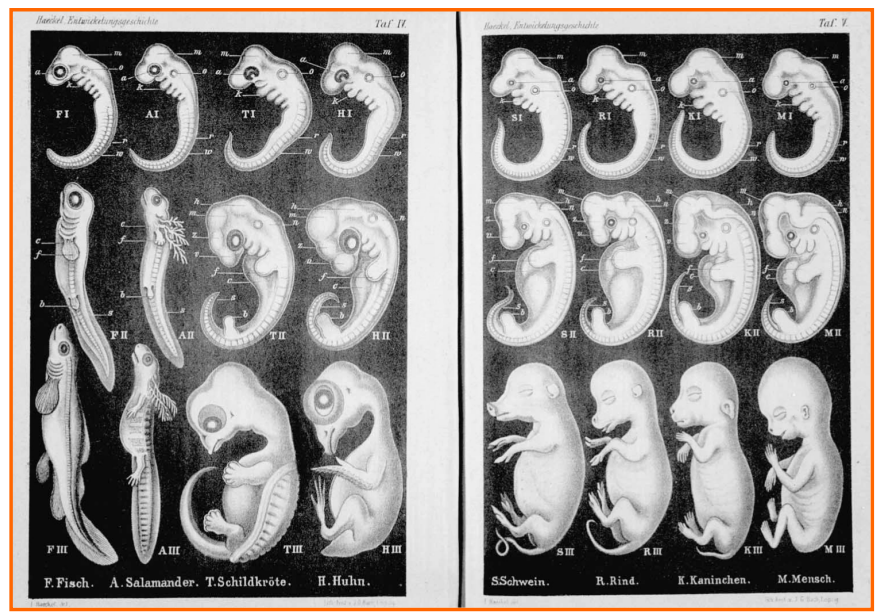

Figura 1. Litografía de J. G. Bach de Leipzig a partir de una ilustración de Ernest Haeckel para Anthropogenie publicada por Engelmann - Nick Hopwood. en Pictures of Evolution and Charges of Fraud: Ernst Haeckel's Embryological Illustrations, Isis 97 (2006). Fuente: https:// commons. wikimedia.org/w/index.php?curid $=8007834$

\section{Método: la cognición expresiva visual y plástica, modos de presentar y conocer el mundo}

Utilizamos en nuestro desarrollo una metodología cualitativa y descriptiva aplicando los modelos de la Investigación Basada en las Artes (IBA) y en especial la Investigación Basada en la Imagen (BBI) (Marín 2017; Roldán y Marín 2012; García 2010; Hernández 2008; Banks 2008) para identificar y entender de forma comprensiva (Stake 


\section{artnodes}

http://artnodes.uoc.edu

2006) los fundamentos que rigen en las imágenes y los objetos en los que ocurre la «episteme» 0 se produce la «representación cognoscitiva» (Piaget 1973). Asimismo, reflexionamos por medio de casos paradigmáticos de autores y disciplinas en las que lo artístico y lo científico dialogaron históricamente, enlazando necesidades y posibilidades, tanto expresivas como cognitivas (Efland 2002, 2004).

\section{1. El conocimiento configurado plástica y visualmente}

Históricamente se han producido diversas colaboraciones entre el quehacer científico y el artístico. El caso de Leonardo da Vinci (14521519) fue paradigmático, ya que trabajó en áreas como la zoología, la anatomía, la fisiología, la ingeniería, la física, la astronomía. Leonardo fue precursor de la epistemología visual, poniendo su arte y saber al servicio de un conocer científico y de una investigación basada en el método por observación que él mismo estableció (Da Vinci 2004). Como nos recuerda Prieto (2006), el siglo xvı se consideró el siglo de «la llustración» 0 «de las luces», gracias en gran medida, a la difusión del conocimiento a través de libros e ilustraciones de todo tipo y el interés del público, que fue creciendo desde el Renacimiento italiano:

«Ténganse presentes los problemas de Leonardo (1452-1519) y Vesalio (1514-1564) por practicar la disección de cadáveres humanos y, sobre todo, por pretender dejar constancia gráfica de sus observaciones en dibujos. [...] en las expediciones de exploración, la tarea de recopilar datos de la Naturaleza y registrarlos mediante dibujos o pinturas corría a cargo de los médicos de a bordo, que solían poseer cierta formación como naturalistas, 0 del capitán u oficiales del buque, más o menos duchos en el levantamiento de planos y el trazado de cartas de navegación. Sin embargo, en el siglo de la llustración, y especialmente en su segunda mitad, se produjeron, por un lado, significativos avances técnicos y, por otro, una progresiva parcelación de los campos del conocimiento. De este modo, las tareas que hasta entonces habían asumido el hombre polifacético o el naturalista, pasaron a ser desempeñadas por el botánico, el zoólogo, el geólogo... y el pintor, que como un especialista más, pasó a ser un elemento imprescindible en cualquier expedición terrestre o marítima» (Prieto 2006, 167).

Desde el siglo xVIII, el «artista viajero» se convirtió en un integrante crucial de las expediciones científicas y un factor determinante de su éxito, ya que, sin documentar los descubrimientos o sin apoyarse en las ilustraciones, era muy difícil transmitir a la comunidad científica los hallazgos y defender las teorías. Encontraremos en las exploraciones científicas a diversos artistas (pintores, grabadores, realizadores, dibujantes...), cuya función fue la de registrar y documentar iconográficamente los descubrimientos. En los viajes del botánico y matemático José Celestino Mutis (1732-1808), y de otros naturalistas como Carlos Linneo (1707-1778), se embarcaron numerosos grabadores. Así relataba en 1729 el trabajo artístico de un dibujante Luis Né a Celestino Mutis en una carta:
La cognición expresiva como experiencia de relación del arte...
«El dibujante de plantas que ha venido, es bueno y de paciencia; tiene sus principios de Botánica y sabe muy bien definir las partes de una planta, en especial las de la fructificación. Los dibujos que hasta hoy he tenido cuidado de dirigir, no están cargados sino de lo preciso, para que cualesquiera sistemático pueda conocer la clase y orden. Unido a este [al dibujo] la descripción metódica, parece que es suficiente para conocer la planta que se presenta» (citado por Bleichmar 2008, 36).

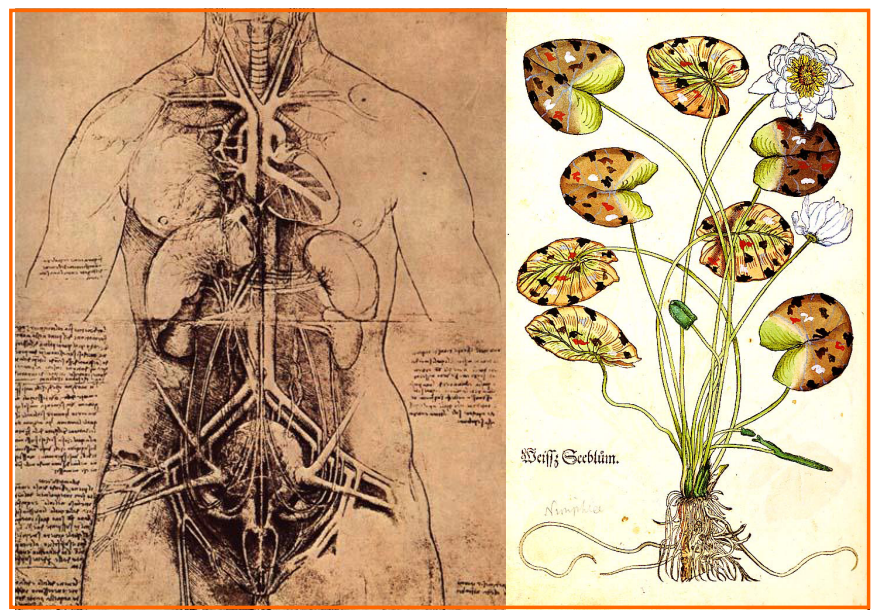

Figura 2. Leonardo da, «Vinci The Principle Organs and Vascular and Urino-Genital Systems of a Woman» (1507). Fuente: https://commons. wikimedia.org/w/index. php?curid=59587.

Figura 3. «Herbarium Vivae Eicones», xilografía coloreada a mano, llustración de Hans Weiditz (1530) y grabado de 0tto Brunfels. Fuente: https://commons.wikimedia.org/w/index. php?curid $=3545806$

Estas imágenes proporcionaban a los naturalistas europeos repertorios visuales que les permitían reunir y comparar los especímenes naturales de todo el mundo dentro de los espacios cerrados de sus estudios. Así, aparecen colecciones de bestiarios ilustrados de carácter enciclopédico, con reinos completos de minerales, animales o vegetales. En esta labor destacaron el artista e ilustrador Hans Weiditz (1495-1537), el pintor Pierre-Joseph Redouté (1759-1840), el artista botánico y entomólogo Georg Diery Ehret (1708-1770) y más tarde, Ernst Haeckel (1834-1919). El éxito de estas expediciones dependía de la maestría de estos grabadores y dibujantes para captar la complejidad de las plantas y animales, lo cual pasaba en primera instancia, por comprender estos la necesidad científica de captar con precisión lo que debía ser representado. Una de las habilidades debía ser la de contextualizar la planta o el animal en su entorno o hábitat. De ahí que muchas de estas imágenes sean registros de un comportamiento a lo largo del tiempo, y no capturas de un instante congelado o estático. Es interesante destacar que Charles Darwin (1809-1882) diseñó en su mente la evolución de las especies visualizándolas a través del tiempo, aunando la estética de las formas, los procesos de plasticidad anatómica, las afinidades orgánicas y semejanzas visuales presentes en las arquitecturas de las diferentes especies. Así explica su idea 


\section{artnodes}

http://artnodes.uoc.edu

de las causas de la variabilidad presente en las especies, entre las cuales, el hábitat (contexto) resultaba fundamental:

«Los efectos de la acción definida del cambio de las condiciones de vida; los de las llamadas variaciones espontáneas, que parecen depender de modo muy secundario de la naturaleza de las condiciones; los de la tendencia a reversión a caracteres perdidos desde hace mucho tiempo; los de las complejas leyes de crecimiento, como las de correlación, compensación, presión de una parte sobre otra, etc.» (Darwin 1921, 271).

Las imágenes que hoy sorprenden son las que transmiten estas y otras informaciones, las que enlazan la visualidad con la plasticidad en lo captado, lo que se percibe al observar la planta o el animal comportándose. Numerosas imágenes científicas comparten con el arte esta capacidad de enlazar en lo que se representa la transformación plástica a lo largo del tiempo (figura 4). El Origen de las especies (1921) se puede considerar una obra plástica y visual, además de teórica y científica. Sin haber comprendido y visualizado los procesos de plasticidad que tuvieron lugar en las especies, la transformación a lo largo del tiempo de sus formas, sus organizaciones, sus relaciones entre las partes... la teoría no se hubiese manifestado del mismo modo. A menudo se contemplan las imágenes y los objetos del arte y de

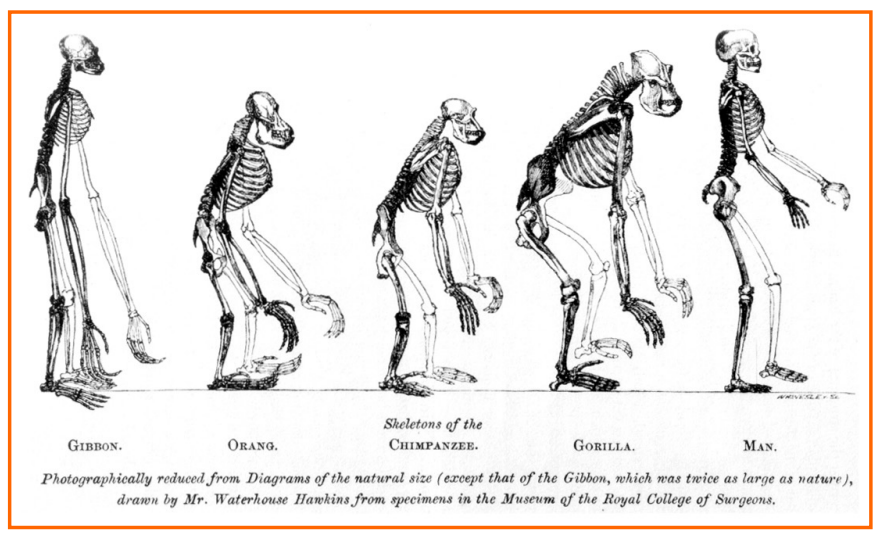

Figura 4. Frontispicio de Evidence as to Man's Place in Nature (1863), de Thomas Henry Huxley de su imagen comparando el esqueleto de los simios al de los humanos. Fuente: https://commons.wikimedia.org/wiki/File:Huxley_-_Mans_Place_in_Nature.jpg

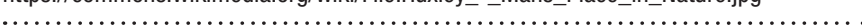

la ciencia como registros de algo estático. Pero presentan y representan acontecimientos. Exactamente esto es lo que presentan las ilustraciones científicas definidas dentro de la cognición expresiva visual y plástica. En ocasiones, se construyen objetos para ayudar a la comprensión de fenómenos complejos, como, por ejemplo, los virus. Construirlos a otra escala ayuda a los virólogos a comprender mejor el comportamiento de estos microorganismos (figura 5), tal y como en el siglo xVIII ayudaban las ilustraciones de Haeckel (figura 6) a comprender las plantas y microorganismos estudiados. Al pensar esta relación en el contexto de la educación preuniversitaria, hay que tener en cuenta que los artistas plásticos y visuales, los ilustradores y diseñadores gráficos se acostumbran en los años de formación a pensar, visualizar y materializar el comportamiento cambiante de las cosas, habituándose a conocer lo que cambia de aspecto para representarlo 0 construirlo. Este acto de plasticidad consciente ejercida sobre las cosas, también ocurre a nivel cognitivo:

«La neurología ha mostrado que un cerebro se transforma orgánica y estructuralmente en el acto mismo de conocer; y que esa transformación, así como el contenido del conocimiento, están determinados por el modo en el que ese conocimiento se adquiere. Un aprendizaje productivo exige adoptar modos plásticos, adecuados a la naturaleza del objeto de estudio» (Moraza 1999, 2).

El proceso de creación artística genera otros modos de dar forma al pensamiento, unos procesos de crítica y práctica deconstructiva de la realidad y manipulación de la materia que puede posibilitar puntos de vista complementarios a los del pensar científico, y sin tener que perder de vista las necesidades propias del contexto de la investigación científica y sus particulares modos de conocer. Asimismo, esto exige, por parte de la ciencia y de los docentes científicos, no reducir la creación artística y las artes plásticas y visuales a una expresión de carácter puramente mediático 0 de entretenimiento 0 situadas exclusivamente en el contexto de las industrias culturales. Los procesos de visualidad y plasticidad, desde una práctica cognitiva expresiva, pueden aportar al desarrollo cognitivo de los discentes y a la configuración visual y plástica de su mentalidad el valor de lo epistémico, estético, cambiante e integrador.

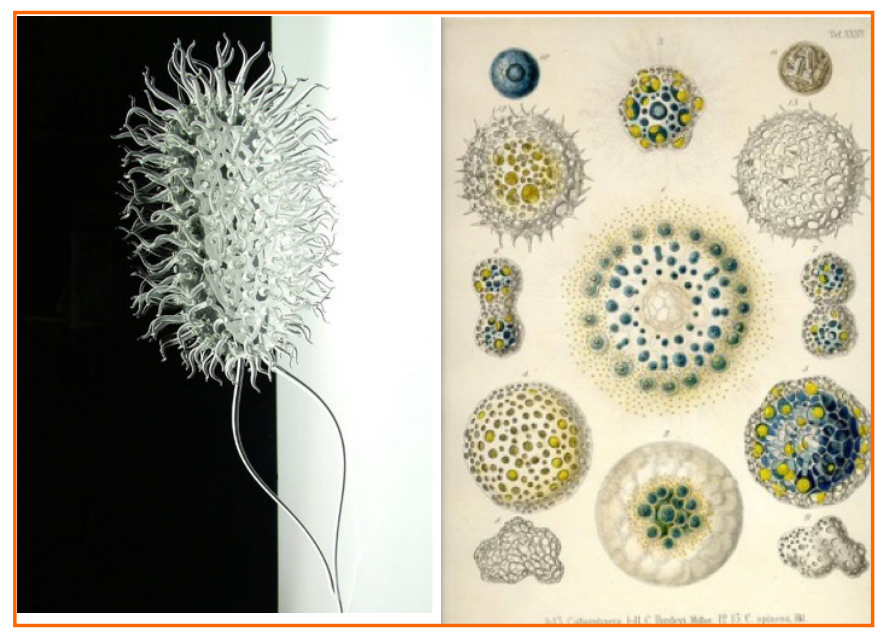

Figura 5. Escultura en cristal de un virus realizada por el artista plástico Luke Jerran. Fuente: https://omicrono.elespanol.com/2014/01/los-virus-mas-mortiferos-en-esculturasde-cristal/virus-cristal-5/

Figura 6. Ernst Haeckel: Células del grupo Radiolarian (1862). Fuente: Arts Forms From The Ocean (2013). Nueva York: Prestel. 


\section{artnodes}

http://artnodes.uoc.edu

\subsection{Expresar y conocer la dimensión del tiempo}

Controlar la representación de las tres dimensiones espaciales sobre el papel científicamente fue algo fundamental para los artistas del Renacimiento italiano. Alberto Durero (1471-1528) realizó diferentes tratados y manuales dedicados a este tema, como De la medida (Durero 2000) y este dominio de la tridimensionalidad visual fue a su vez esencial para el avance en la comprensión de las estructuras biológicas, como, por ejemplo, para la embriología. La representación de cuatro dimensiones (tres espaciales, una temporal) fue también muy importante en los siglos xIx y xx, tanto para el arte como para la ciencia. La dimensión del tiempo representada ya aparece en numerosas ilustraciones de autores como Haeckel (figura 1), que reflejan la simbiosis entre la necesidad científica de registrar los diferentes niveles formales del espécimen y la maestría de hacerlo en un plano bidimensional, representando sus diferentes complejidades: interior y exterior, arriba y abajo, superficie y profundidad, transformación en el tiempo, etcétera. Son trabajos que representan en dos dimensiones el espacio holístico en el que vive el espécimen. Estos artistas fueron capaces de expresar cognitivamente en la superficie del papel el comportamiento de la planta a través del tiempo. Sus ilustraciones no solo representan las cosas, sino que las conocen. Obras como La figura humana en movimiento (1955) de Muybridge ilustran claramente este deseo de registrar y captar lo temporal, que culminaría con la invención del cinematógrafo por los Hermanos Lumière en 1895.

Si analizamos lo ocurrido en el siglo xx, y sin salirnos del contexto profesional de los artistas, entre los numerosos ejemplos de confluencia encontramos a Albert Einstein (1879-1955), la teoría de la relatividad y el cubismo de Picasso (1881-1973). El cubismo abrió paso a la experiencia expresiva relativista, con la superación de la perspectiva renacentista en la que el observador controlaba todo desde un punto de vista único y estático. Picasso integró diferentes puntos de visión en una misma perspectiva e introdujo la dimensión del tiempo al desplazarse y moverse (figura 7), al ir cambiando su punto de referencia. Picasso, como otros autores, hizo converger en la representación el conjunto de conocimientos intelectuales y experiencias sensibles de su época, dotando a la obra de ciencia y teoría además de estética, técnica y forma. En su obra El sueño(1932), podemos ver (figura 8) a la modelo de perfil, de frente, desde arriba... integrando la dimensión del tiempo a través del tránsito que el artista realiza mientras representa la escena. Es un cuadro-secuencia, resultado de aplicar un método de conocimiento, representación y composición relativista. Picasso incorpora lo corporal y el movimiento del propio observador al acto de percibir las cosas, abriendo nuevas posibilidades para el arte igual que había hecho Einstein para la ciencia. Como expresó Arnheim (1971), la percepción es cognición, un acto de la mente, algo psíquico y no fisiológico.

Siguiendo con esta práctica expresiva relativista que ya habían incorporado las vanguardias, encontramos obras como La materia del tiempo (1994-2005), instalación del artista Richard Serra, que presenta una visión del tiempo alejada del concepto de linealidad espacial y de una consideración cartesiana del mundo, y que enlaza conceptos de la Física y la Matemática y del pensar relativista contemporáneo. La forma y la estética de la obra (figura 9), acogen
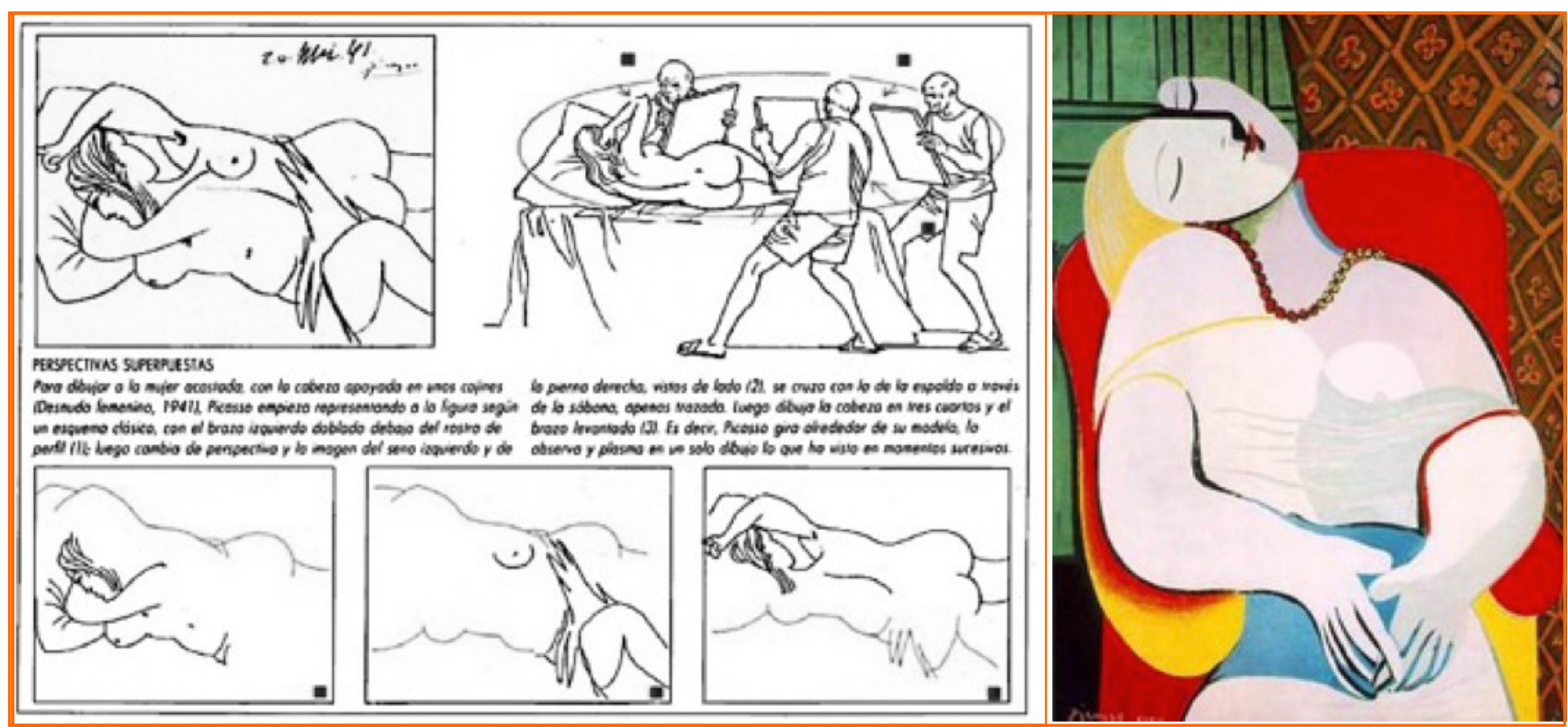

Figuras 7. Entender la pintura: Picasso, Orbis Fabbri, Barcelona (1989: 16).

Figura 8. El sueño, Picasso (1932). Fuente: https://upload.wikimedia.org/wikipedia/en/9/9d/Le-reve-1932.jpg 


\section{artnodes}

http://artnodes.uoc.edu

al visitante y le llevan a transitar a través de un laberinto en el que tiempo y espacio parecen quedar fusionados. La cuestión aquí, además de las posibles metáforas científicas, es el modo en el cual el artista «representa» físicamente estas teorías e ideas, conectando datos, saberes y experiencias con los procesos plásticos, estéticos y formales propios de su proceso creador.

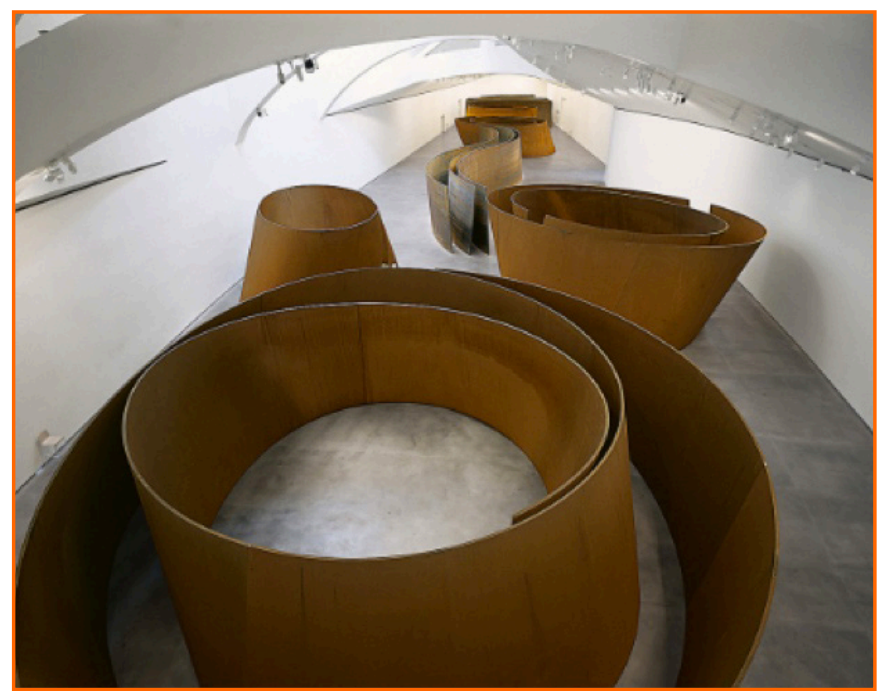

Figura 9. Richard Serra. La materia del tiempo, 1994-2005. Ocho esculturas de acero patinable. Dimensiones variables. Fuente: https://www.guggenheim-bilbao.eus/exposiciones/ richard-serra/
La cognición expresiva como experiencia de relación del arte...

\subsection{Expresar y conocer lo que no podemos ver}

Uno de los ejemplos paradigmáticos de la relación arte y ciencia fue el de Salvador Dalí (1904-1989), quien puso imagen al subconsciente y sus complejidades. La obra de Freud La interpretación de los sueños (2013) era uno de sus libros de cabecera en la adolescencia y logró traducir a un lenguaje visual las ideas freudianas. Como ejemplo de cognición expresiva en la obra de Dalí podemos citar obras como La persistencia de la memoria (1931) o El gran masturbador en paisaje surrealista con $A D N$ (1957), donde incluyó una representación de la molécula. En palabras del propio Dalí:

«Si los físicos producen antimateria, les está permitido a los pintores, ya especialistas en ángeles, pintarla. Durante el período surrealista, he deseado crear la iconografía del mundo interior, el mundo de lo maravilloso, de mi padre Freud; lo he logrado. En la actualidad, el mundo exterior -el de la física- ha trascendido al de la psicología. Mi padre, hoy, es el doctor Heisenberg. Con los pi-mesones y los más gelatinosos e indeterminados neutrinos deseo pintar la belleza de los ángeles y de la realidad» (1958).

Otro ejemplo significativo fue lo que ocurrió el 2 de abril de 1953, cuando James Watson y Francis Crick presentaron sus descubrimientos acerca de la estructura de la molécula del ADN, con las aportaciones de la química y cristalógrafa Rosalind E. Franklin, en un artículo enviado a la revista Nature que consistía en una hoja con gráficos y anotaciones con no más de 900 palabras. Tan importante como el texto fueron las dos ilustraciones incorporadas (figura 11).
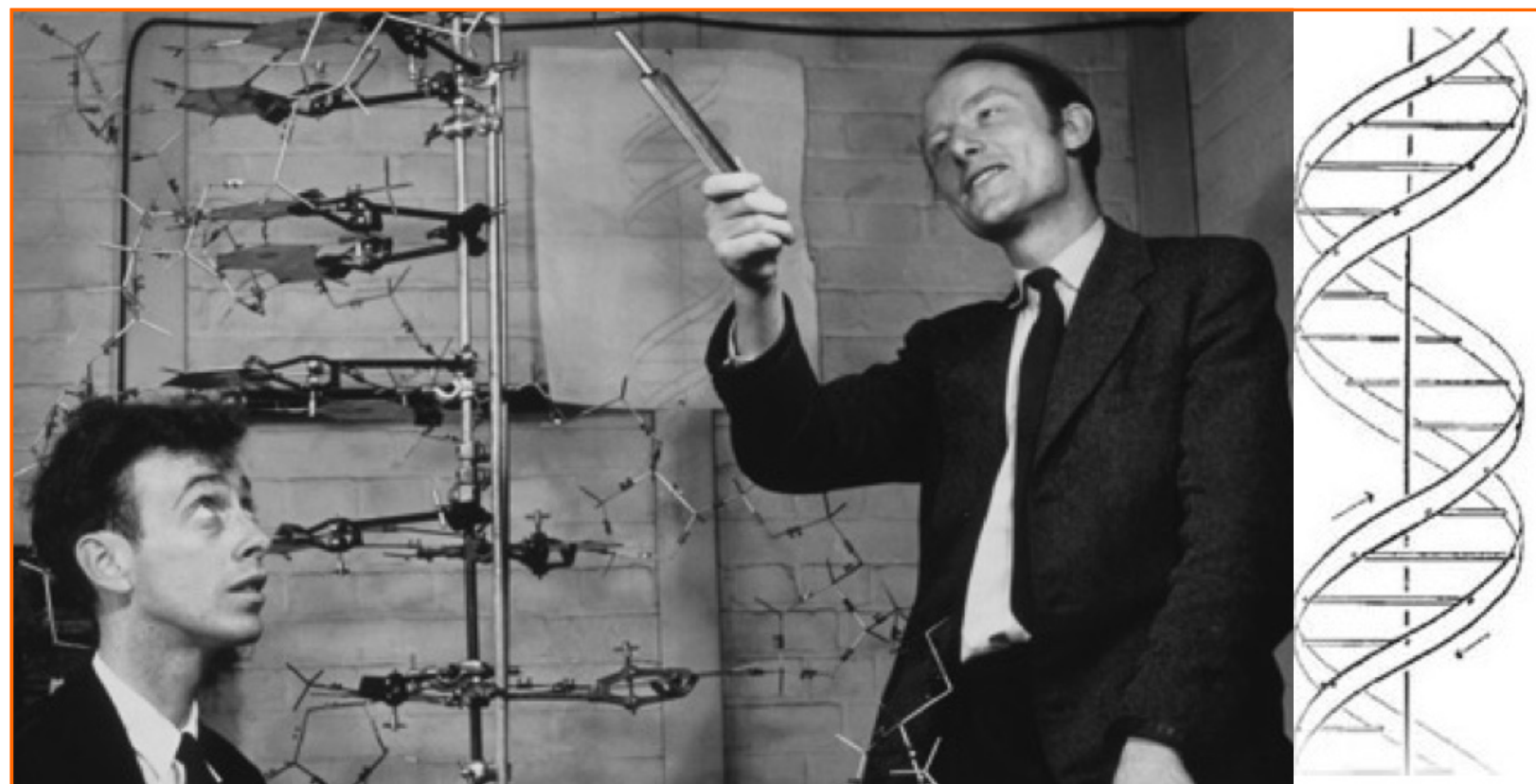

On it
We
radici
the \&
acid.
helies
the si
have
assun
chain
ester
ribofi
linka
not $t$
dyad
axis.
hand
the $c$
atom
in o
chain
berg'!
thai

Figura 10. James Watson y Francis Crick junto a uno de sus modelos de la molécula del ADN en 1953. Fuente: http://esmateria.com/2013/04/25/el-secreto-de-la-vida-cumple60-anos/\#prettyPhoto/1/.

Figura 11. llustración que acompañaba al texto de Watson y Crik (1953), Nature. Fuente: http://www.nature.com/nature/dna50/watsoncrick.pdf 


\section{artnodes}

En 1957, unos 4 años después de esta publicación, Dalí pinta El gran masturbador. James Watson contempló el cuadro y quiso que Dalí ilustrara el libro que estaba escribiendo. Es conocido cómo Dalí, en toda su trayectoria, amplificó las posibilidades de colaboración entre artistas y científicos e influyó en el contexto académico. Por su parte, Watson y Crick también construyeron maquetas de la molécula del ADN para estudiarla y comprenderla mejor (figura 10). Hoy en día, gracias a la fotografía, a la microscopia y a las tecnologías digitales, es habitual que los científicos trabajen parte de sus teorías visual 0 plásticamente para comprender más a fondo y desde otros puntos de vista aquello que están investigando e intentado conocer.

Asimismo, hay ocasiones en las que la formación especializada del científico convive con la formación artística y encontramos «científicos artistas» 0 «artistas científicos»: Morse (pintor además de inventor), Goethe (filósofo, teórico, pintor, político, anatomista, botánico), Carrol (novelista y profesor de lógica y matemática). Uno de estos casos sorprendentes en los que convergen formación artística y científica fue el de Santiago Ramón y Cajal (1852-1934), quien en su juventud quería ser pintor y toda su vida se dedicó a la fotografía, y publicó algunos tratados como Fotografía de los colores: Bases científicas y reglas prácticas (2007). Sus dibujos sobre las estructuras del cerebro, las formas neuronales... son trabajos en los que se mezcla conocimiento e intuición, plasticidad y epistemología visual. Su formación y vocación artística resultó crucial para el desarrollo y comunicación de sus ideas y el avance de la disciplina de la neurología (figura 12).

En todos estos trabajos proyectados desde el arte 0 desde la ciencia, el conocimiento artístico y el científico complementaron sus lenguajes, procesos y medios para comprender conceptos y expresar visual u objetualmente sus teorías e ideas. En este sentido, resulta valiosísima la formación recibida en las primeras etapas de formación, porque la plasticidad cerebral (Gazzaniga 1998) en los primeros años es más intensa y se configuran, tal y como han demostrado las investigaciones (Damasio 2001), arquitecturas cerebrales que nos acompañarán en nuestra vida, que condicionarán capacidades 0 incrementarán aptitudes (Gardner1997).

1.4. Aprender a expresar cognitivamente lo icónico y abstracto Si pensamos formativamente la práctica de la cognición expresiva, esta puede desarrollarse yendo de lo más icónico a lo más abstracto 0 a la inversa. Series como Toro (1945-46) de Picasso (figura 13), Vaca (1917) de Theo van Doesburg o Estudio de árboles (1909-1915) de Piet Mondrian ilustran este proceso realizado en una superficie bidimensional. Obras como Pájaro en el espacio (1912) de Brancusi ilustran este mismo proceso en lo tridimensional (figura 14). Como dijo Brancusi «Esto no es un pájaro que vuela, sino la idea de un pájaro que vuela». El premio nobel de Física, Richard Phillips Feynman (19181988), ideó y desarrolló un esquema de representación utilizado para las expresiones matemáticas que rigen el comportamiento de

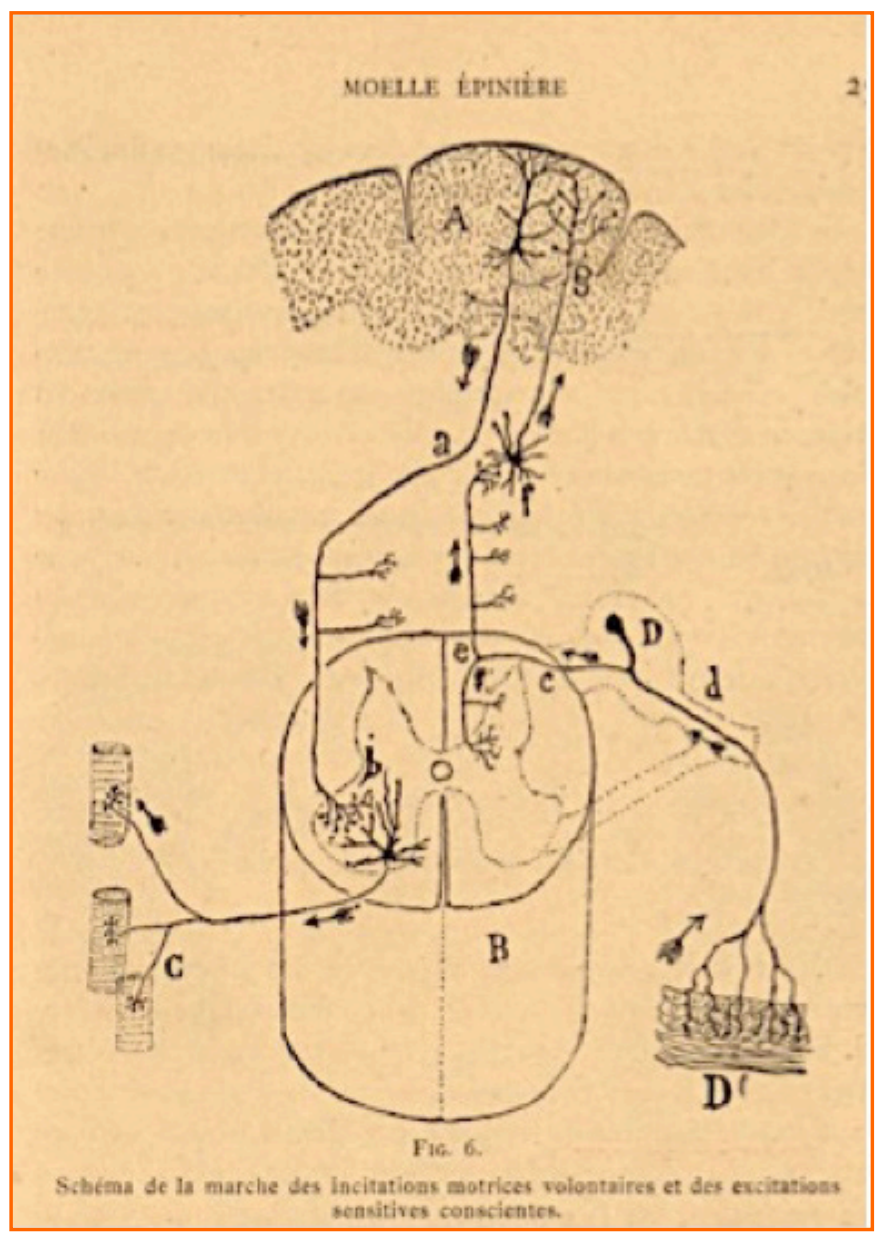

Figura 12. Santiago Ramón y Cajal. Histología del sistema nervioso del hombre y de Ios vertebrados (1894), Paris: C. Reinwald \& Cie. Fuente: http://bdh-rd.bne.es/viewer. vm?id=0000201104\&page $=1$

las partículas subatómicas, conocido hoy como «los diagramas de Feynman»: son gráficos que representan espacio-temporalmente las trayectorias de las partículas en las fases intermedias de un proceso de colisión. Los diagramas de Feynman (figura 15) se componen de agrupaciones de símbolos básicos (flechas, líneas, puntos, letras...), que representan ciertos tipos de partículas elementales y sus colisiones. También el matemático Thomas Francis Banchoff utilizó la construcción escultórica de objetos para comprenderlos mejor y explicar sus conceptos, como por ejemplo, un cubo de cuatro dimensiones espaciales conocido como hipercubo o teseracto (figura 16).

Las imágenes y objetos para ciertos estudios científicos resultan fundamentales, ya que tan importante es lo que uno piensa como su capacidad para ilustrarlo, configurarlo y darlo a conocer plástica y visualmente. Esto indica que quien trabaje en las aulas debe entender primero esta doble posibilidad y función de la imagen y los modos en los que un conjunto de recursos gráficos, un vocabulario de elementos básicos de expresión y configuración (puntos, líneas, planos, volúmenes, colores, materias...) llegan a convertirse en la 


\section{artnodes}

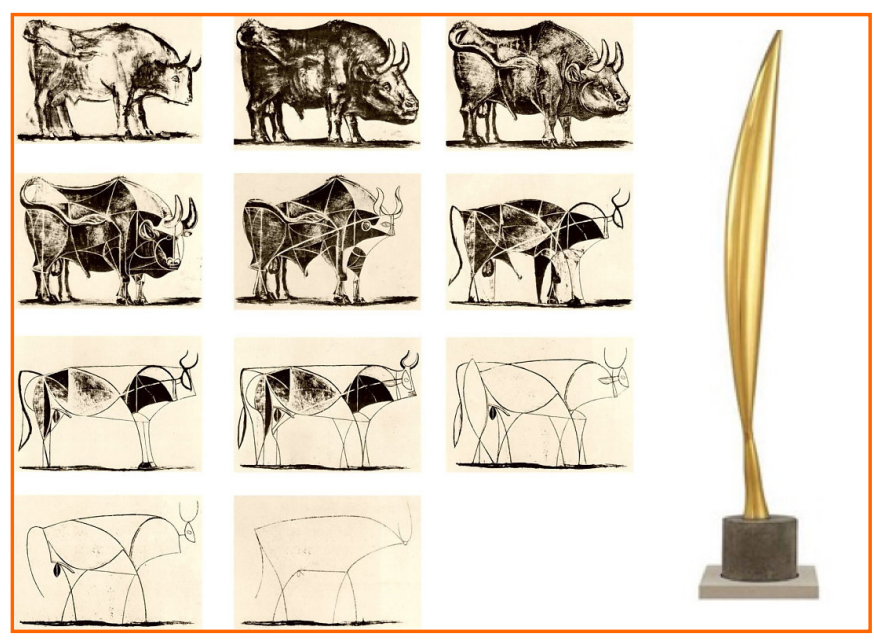

Figura 13. Litografías de la serie Toro (1945-46), Picasso. Fuente: http://www.superception. fr/en/2014/08/17/apple-picasso-and-marketing/

Figura 14. Escultura Pájaro en el espacio (1923), Brancusi. Fuente: https://arte.laguia2000. com/escultura/pajaro-en-el-espacio-de-brancusi

materialización formal de un pensamiento, una teoría o un fenómeno, enlazando lo formal con lo semántico, articulando lo estético con lo epistémico, la visualidad y la plasticidad con lo cognitivo a través de su expresión. Matemáticos y divulgadores científicos (Corrales 2001) avalan la utilización de la pintura y la escultura, tanto para ilustrar estrategias matemáticas como para comprender problemas específicos. Para que este puente de saber sea efectivo, y para que el alumnado pierda el miedo a lo nuevo y desconocido, etapa tras etapa, contenido a contenido, proyecto a proyecto, es necesario enseñar, no solo a pensar alfabética y numéricamente, sino a pensar artísticamente el mundo y sus fenómenos, a representar de forma icónica y abstracta las ideas desde proyectos que integren necesidades científicas con posibilidades artísticas.

\section{Conclusiones: educar en cognición expresiva plástica y visualmente desde la infancia}

A partir de nuestra revisión teórica y visual, se significa la necesidad de introducir en el contexto educativo preuniversitario espacios de aprendizaje y experiencias en los que los discentes adquieran de forma progresiva consciencia de que la creación de imágenes o de objetos puede llevar a una mejor comprensión de fenómenos como la relatividad, una neurona o el ADN o conceptos como la dimensión del tiempo. No obstante, se manifiesta como tarea imposible lograrlo desde un maestro generalista o profesor que sea inexperto en procesos y técnicas de creación artística o en la comprensión de que la ciencia comparte numerosos procesos y modos de hacer con el arte. La cognición expresiva plástica y visual posibilita la adquisición de una mente holística e integrada que permite articular en los procesos la forma, el significado y el contenido para expresarlo. Para que esta práctica llegue a convertirse en un hábito para cuando el discente Ilegue a la Universidad, se deben diseñar proyectos adecuados a cada etapa, propósito y tema, que enlacen las necesidades del conocer científico con las posibilidades del saber artístico. Las posibilidades que genera el aprendizaje común del arte y de la ciencia, desde la práctica de la cognición expresiva, implican la incorporación de acciones y proyectos para el aula preuniversitaria en los que se sepa articular cognición y expresión y trabajar la representación cognoscitiva tanto visual como plásticamente. El contexto escolar preuniversitario es el lugar donde este aprendizaje debería empezar a aplicarse para que sea un hábito. Utilizar la ilustración y lo escultórico como potencias expresivas y transmisoras de conocimiento en las aulas preuniversitarias pasa por la comprensión que tenga el maestro 0 el profesor de que ilustrar o esculpir también son modos de visualización del saber (Arnheim 1971; Eisner 2004; Piaget 1973, 1977). Solo así introducirá en las aulas actividades o proyectos que

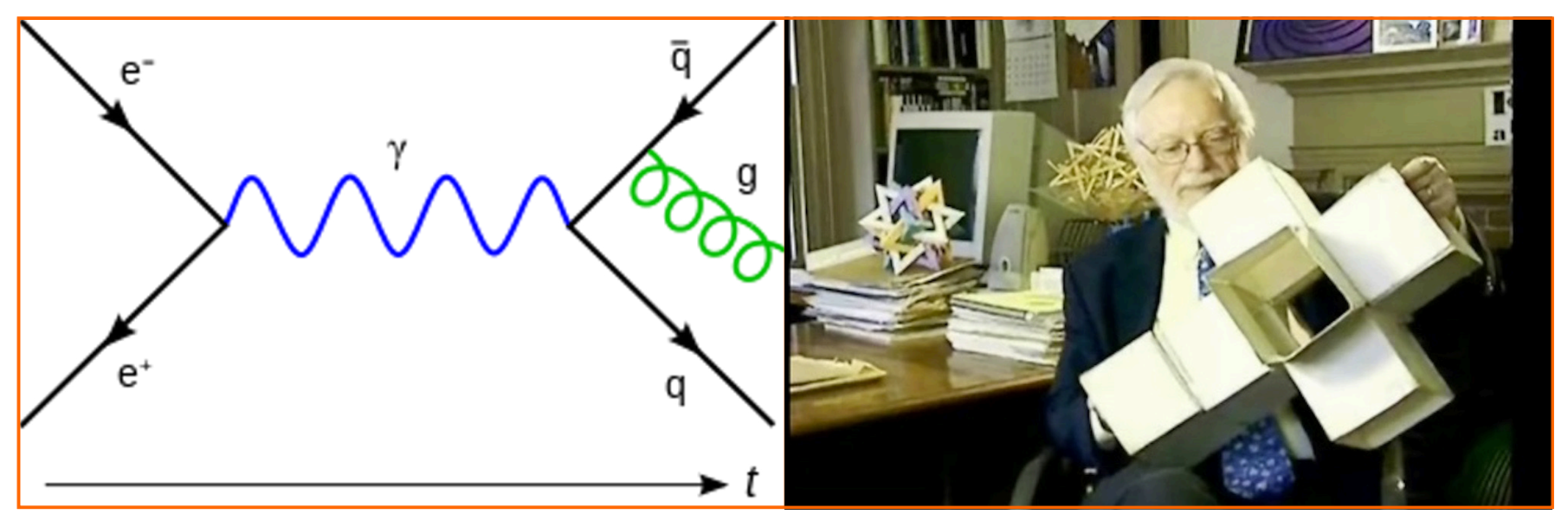

Figura 15. Diagrama de Feynman. Fuente: https://commons. wikimedia.org/w/index.php?curid=1764161

Figura 16. El matemático Thomas Francis Banchoff sosteniendo una réplica de un Hipercubo, utilizado por Salvador Dalí en algunos de sus cuadros. Fuente: https://www.youtube.com/ watch?v=H3LhLY5F7AU 


\section{artnodes}

http://artnodes.uoc.edu

permitan a los niños transmitir ideas o conceptos complejos (Prigogine y Nicolis, 1997) o abstractos, tanto visual como objetualmente.

El cuestionamiento de la realidad como algo absoluto y preestablecido y la práctica interdisciplinar son necesarios para conseguir una mente dotada de estrategias innovadoras y métodos de aprendizaje creativos, que sepa además transitar por caminos donde las preguntas no están formuladas y cuyas respuestas todavía carecen de referencias. El arte es tradicionalmente de «naturaleza integradora» (ars: articular) y la ciencia «diseccionadora» (scio: escindir). Por eso ambos modos complementan. No obstante, estas prácticas actualmente se han perdido y artes y ciencias permanecen separadas curricularmente, tanto en Primaria como en Secundaria, o se articula lo artístico desde una concepción mediática en vez de cognitiva (Efland 2004; Zeki 2005; Caeiro 2018). La necesidad de unir, en el contexto educativo preuniversitario, a la sociedad del conocimiento y a la sociedad del espectáculo, nos invita a considerar la cognición expresiva visual y plástica y el trabajo llevado a cabo, tanto desde la educación artística como de la educación científica como un modo idóneo para establecer relaciones contemporáneas en la línea de las necesidades actuales y de la adquisición de competencias integrales.

Encontramos numerosos documentos dedicados a explorar esta intersección, en los que se presentan las deseables convergencias del arte, la ciencia y la tecnología (Wilson 2002) y que también plantean las necesidades de educar en contextos integrados antes de la Universidad (V.AA. 2007). Es necesario trabajar en las primeras etapas del desarrollo cognitivo en los discentes los lenguajes gráficos, visuales, plásticos... desde un espacio que integre ciencias, artes y tecnologías. Estas formaciones y experiencias de aprendizaje integradoras no son nunca independientes de la profesión que escogen los discentes, sino más bien que motivarán su elección.

Como hemos visto, la cognición expresiva visual y plástica y la representación cognoscitiva no se sitúan en las inercias del visual thinking, que ha derivado la práctica del «pensar visualmente» a las necesidades comunicativas, lo que aleja las posibilidades cognitivas de la imagen y reduce los recursos gráficos, visuales, alfabéticos a un modelo mediático al servicio de ideas y conceptos que acaban convertidos en «mensajes», que desatienden el valor expresivo y cognitivo de las propias herramientas, recursos y lenguajes. Por otro lado, el «pensamiento plástico» utiliza y requiere unos modos difícilmente encajables por los establecidos por el visual thinking. El pensamiento visual que ocurre en Las Meninas de Velázquez y el pensamiento plástico que ocurre de una escultura del ADN poco tienen que ver con los «mapas mentales» actuales, ya que algunos son puramente «conceptuales» y se alejan de todo proceso de plasticidad. Sin duda, las necesidades de la sociedad de la comunicación y la información son formativamente diferentes a las de la sociedad del conocimiento.

Necesitamos una nueva generación de niños y niñas capaces de crear imágenes cognitivas, de ilustrar estéticamente lo inconcebible,
La cognición expresiva como experiencia de relación del arte...

de construir plásticamente lo que viene, de expresar cognitivamente el futuro, operaciones todas que requieren de una formación dirigida, que les ayude a interpretarlo y a desarrollar visiones teóricas y estéticas innovadoras. Debemos considerar en el contexto preuniversitario a la ilustración y lo escultórico como medios capaces de expresar y comunicar las más variadas y diversas complejidades, tanto en arte como en ciencia, que relacionen en las creaciones lo gráfico con lo alfabético y lo numérico, lo volumétrico con lo epistémico, desde un modelo que sea más cognitivo y menos mediático. Si hace 100 años la física cuántica y el subconsciente eran desconocidos, ¿qué nuevos actos humanos deberán afrontar los niños que hoy tienen cinco años? ¿Qué niño actual es capaz de representar o comprender la representación del tiempo, de interpretar un cuadro cubista o un diagrama del nervio óptico? Pues llevamos más de 100 años haciéndolo.

\section{Referencias bibliográficas}

Acaso, M. 2009. La educación artística no son manualidades. Nuevas prácticas en la enseñanza de las artes y la cultura visual. Madrid: Los Libros de la Catarata.

Althusser, L. 1966. Carta sobre el conocimiento del arte (respuesta a André Daspre). Nouvelle Critique.

Arnheim, R. 1971. Arte y percepción visual. Piscología del ojo creador. Madrid: Alianza.

Baigri, B. S. (Ed.) 1996. Picturing Knowledge. Historical and Philosophical Problems Concerning the Use of Art in Science. University of Toronto Press. Toronto: Buffalo, London Series, Toronto studies in philosophy.

Banks, M. 2008. Los datos visuales en Investigación Cualitativa. Madrid: Ediciones Morata.

Barbosa, A. M. 2001. «The Escuelas al Aire Libre de Méjico: Freedom, Form and Culture». Studies in Art Education, 42, (4): 285- 297. https://doi.org/10.2307/1321075

Bleichmar, D. 2008. El imperio visible: la mirada experta y la imagen en las expediciones científicas de la ilustración. Salamanca: Ediciones Universidad de Salamanca. Cuadernos dieciochistas.

Brea, J. L. (Comp.) 2005. Estudios visuales. La epistemología de la visualidad en la era de la globalización. Madrid: Akal.

Berger, J. 2013. Modos de ver. Barcelona: Gustavo Gili Editora.

Caeiro Rodríguez, M. (2018). «Aprendizaje Basado en la Creación y Educación Artística: proyectos de aula entre la metacognición y la metaemoción». Arte, Individuo y Sociedad, 30(1), 159-177. http://dx.doi.org/10.5209/ARIS.57043

Corrales, C. 2001. Un paseo por el siglo XX de la mano de Fermat $y$ Picasso. Madrid: Consejo Social de la Universidad Complutense.

Dalí, S. 1958. Manifiesto de la antimateria. Nueva York: Castairs Gallery. Catálogo de la exposición.

Damasio, R. A. 2001. El error de Descartes. Barcelona: Editorial Crítica. 
Daston L. y Galison, P. 1992. «The Image of Objectivity». Representations, Special Issue: Seeing Science. 40, 81-128. http://cspeech. ucd.ie/Fred/docs/Galison.pdf, https://doi.org/10.2307/2928741

Darwin, C. 1921. El origen de las especies: Madrid: Akal. http://www. cervantesvirtual.com/obra-visor/el-origen-de-las-especies-pormedio-de-la-seleccion-natural--0/html/

Da Vinci, L. 2004. Tratado de pintura, Madrid: Akal.

Durero, A. 2000. De la medida. Madrid: Akal.

Efland, A. D. 2002. Una historia de la educación del arte. Tendencias intelectuales y sociales en la enseñanza de las artes visuales. Barcelona: Paidós.

Efland, A. D. 2004. Arte y cognición, la integración de las artes visuales. España: Octaedro EUB.

Eisner. E. W. 2004 El arte y la creación de la mente. El papel de las artes visuales en la transformación de la conciencia. Barcelona: Paidós.

García Gil, M. E. 2010. «El uso de la imagen como herramienta de investigación». Campos en ciencias sociales, comunidad acción y comunicación, 1: 363, 372. Bogotá: Universidad Santo Tomás. https://doi.org/10.15332/s2339-3688.2013.0002.07

Gardner, H. 1997. Arte, Mente y cerebro: Una aproximación cognitiva a la creatividad. Barcelona: Paidós.

Gazzaniga, S. M. 1998. El pasado de la mente. Barcelona: Editorial Andrés Bello.

Haeckel, E. 1862. Art Forms from the Ocean. Munich: Prestel.

Hernández Hernández, F. 2008. «La investigación basada en las artes. Propuestas para repensar la investigación en la educación». Educación Siglo XXI, 26: 85-118. http://revistas.um.es/educatio/ article/viewFile/46641/44671

Luquet, G. H. 1927. El dibujo infantil. Barcelona: Editorial Médica y Técnica.

Lowenfeld, V; Lambert, W. 1972. Desarrollo de la capacidad creadora. Buenos Aires: Kapelusz.

Marín Viadel, R. 2017. Ideas visuales. Investigación Basada en Artes e Investigación Artística. Granada: Universidad de Granada.

Moraza Pérez, J. L. 1999. Decálogo-deseo para un arte de la enseñanza (de las artes). http://old.arteleku.net/publicaciones/editorial/ zehar/60-61-la-escuela-abierta/decalogo-deseo-para-un-artede-la-ensenanza-de-las-artes/at_download/file

Muybridge, E. 1955. The Human Figure in Motion. Nueva York: Dover Publications.

Osakar, P. 2009. Manual de instrucciones. Fotografía: http://www. flickr.com/search/?q=pedro+osakar
Piaget, J. 1973. La formación del símbolo en el niño. México: Fondo de Cultura económica.

Piaget, J. 1977. El nacimiento de la inteligencia en el niño. Barcelona: Crítica.

Prieto, P. S. 2006. «Pintores en las grandes expediciones científicas españolas del siglo XVIII». Ars Medica. Revista de Humanidades. 2, 166-179 http://www.dendramedica.es/revista/v5n2/ Pintores_en_las_grandes_expediciones_cientificas_espanolas_del_siglo_XVIII.pdf

Prigogine, I.; y Nicolis, G. 1997. La estructura de lo complejo. Madrid: Alianza Editorial.

Ramón y Cajal, S. 1894. «Comunicación acerca de la significación fisiológica de las expansiones protoplasmáticas y nerviosas de las células de la sustancia gris». En: Actas del Primer Congreso Médico-Farmacéutico Regional de 1891. Valencia, Domenech: 70-85. http://hicido.uv.es/IMV/0tros/congreso.html\#4

Ramón y Cajal, S. 2007. Fotografía de los colores: Bases científicas y reglas prácticas. Barcelona: Las Tres Sorores.

Roldán, J., Marín Viadel, R. 2012. Metodologías artísticas de investigación en educación. Málaga: Ediciones Aljibe.

Sánchez, J. D. (Coord.) 2013. Epistemología de las artes: La transformación del proceso artístico en el mundo contemporáneo. Argentina: EDUP, Editorial de la Ciudad de La Plata. https://libros. unlp.edu.ar/index.php/unlp/catalog/view/104/86/279-1

Serra, R. 2013. Tools \& Strategies. Exclusive Art 21. Documental. https://www.youtube.com/watch?v=G-mBR26bAzA

Stake, R. E. 2006. Evaluación comprensiva y evaluación basada en estándares. Barcelona: Ariel.

Vigotsky, L. S. 2014. La imaginación y el arte en la infancia. Madrid: Ediciones Akal.

W. AA. 2007. Libro Blanco de la Interrelación entre Arte, Ciencia y Tecnología en el Estado Español. Fundación Española para la Ciencia y la Tecnología (FECYT). https://www.fecyt.es/es/node/2230/ pdf-viewer

Watson, J. D.; Crick, F. H. C. 1953. «Molecular structure of nucleic acids». Nature: 171. http://www.nature.com/nature/dna50/watsoncrick.pdf. https://doi.org/10.1038/171737a0

Wilson, S. 2002. Information Arts. Intersections of art, science and technology. Londres: MIT press. https://doi.org/10.7551/mitpress/3765.001.0001

Zeki, S. 2005. Visión interior, Una investigación sobre el arte y el cerebro. Madrid: La balsa de la Medusa. 


\section{artnodes}

http://artnodes.uoc.edu

La cognición expresiva como experiencia de relación del arte...

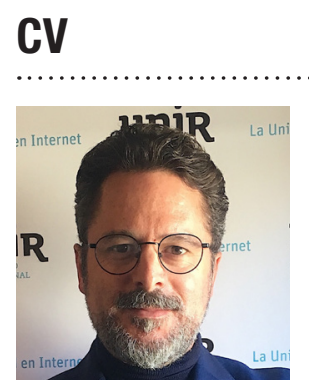

Martín Caeiro Rodríguez

martin.caeiro@unir.net

Universidad Internacional de La Rioja-UNIR

Director Departamento Didáctica de las Artes Plásticas y Visuales,

Facultad de Educación

Avenida de La Paz, 157

26002 Logroño (La Rioja)

Doctor en Bellas Artes (Universidad de Vigo, 2008) y coeditor de La cultura transversal: colaboraciones entre arte, ciencia y tecnología (Universidad de Vigo, 2010). Ha publicado diversos artículos como: «El aborigen y sus imágenes» (Revista Latinoamericana de Filosofía, Política y Humanidades Araucaria, 2009); «Exponer lo imaginal: reproducir y representar» (Revista Arte, Individuo y Sociedad, Universidad Complutense de Madrid, 2009); «Tecnopatías de la educación artística: reflexiones en torno a la enseñanza y aprendizaje digital del arte» (Biblioteca Online, UNIR, 2015) y «Aprendizaje Basado en la Creación y Educación Artística: proyectos de aula entre la metacognición y la metaemoción» (Revista Arte, Individuo y Sociedad, Universidad Complutense de Madrid, 2018). Actualmente es Director del Departamento de Didáctica de las Artes Plásticas y Visuales en la Facultad de Educación y Director del Grupo de Investigación «Artes Plásticas, Culturas Visuales y Educación (TESERTACTO)» de la Universidad Internacional de La Rioja (UNIR). 


\section{artnodes}

http://artnodes.uoc.edu

La cognición expresiva como experiencia de relación del arte...

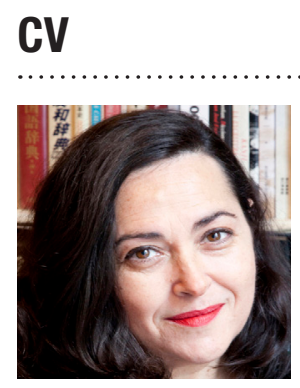

Antonia María Muñiz De la Arena

antonia.muniz@unir.net

Universidad Internacional de La Rioja-UNIR

Profesora Facultad de Educación

Avenida de La Paz, 157

26002 Logroño (La Rioja)

Doctora en Bellas artes (Universidad Complutense de Madrid). Ha realizado numerosas exposiciones individuales y colectivas, nacionales e internacionales, organizadas por instituciones de reconocido prestigio (MAEC, AECID, Instituto Cervantes, bienales, museos, Ferias-ARCO, Indian Art Fair, Kunstköln, Estampa). Ha sido comisaria en organismos institucionales de reconocido prestigio (MAEC,AECID, Dirección General de Relaciones Culturales y Científicas) en bienales y museos internacionales. Ha realizado diversas experiencias en formación de profesorado (infantil / primaria / secundaria) en centros de formación e innovación de la Comunidad de Madrid y en proyectos educativos internacionales de innovación con la subdirección general de evaluación y análisis y la OCDE / CERI (Centre for Educational Research and Innovation). Actualmente es profesora del Departamento de Didáctica de las Artes Plásticas y Visuales en la Facultad de Educación y forma parte del Grupo de Investigación «Artes Plásticas, Culturas Visuales y Educación (TESERTACTO)» de la Universidad Internacional de La Rioja (UNIR). 